\title{
Título da página electrónica: CIDLOT/Universidade de Cabo Verde
}

URL: www.unicv.edu.cv/cidlot

Andréia Moassab e Patrícia Anahory

C OpenEdition

\section{Journals}

Edição electrónica

URL: http://journals.openedition.org/rccs/4457

DOI: $10.4000 /$ rccs. 4457

ISSN: 2182-7435

\section{Editora}

Centro de Estudos Sociais da Universidade de Coimbra

Edição impressa

Data de publição: 1 dezembro 2010

Paginação: 295-298

ISSN: 0254-1106

Refêrencia eletrónica

Andréia Moassab e Patrícia Anahory, «Título da página electrónica: CIDLOT/Universidade de Cabo Verde », Revista Crítica de Ciências Sociais [Online], 91 | 2010, posto online no dia 29 novembro 2012, consultado o 22 setembro 2020. URL : http://journals.openedition.org/rccs/4457 ; DOI : https:// doi.org/10.4000/rccs. 4457 


\section{Espaço Virtual}

\section{Título da página electrónica: Vitruvius URL: www.vitruvius.com.br; www.vitruvius.es}

Em Março de 2010 o Portal de Arquitectura Vitruvius celebrou o seu décimo aniversário com o lançamento de uma nova versão editada a partir de Barcelona. O Vitruvius nasceu no Brasil, no ano de 2000, fruto da experiência de Abílio Guerra e Silvana Romano como editores da revista Óculum. Abílio Guerra, arquitecto (FAU PUC-Campinas, 1982) e historiador (IFCH Unicamp, 1990), publicou o primeiro número da revista em Agosto de 1985. O segundo número foi editado alguns anos mais tarde, em 1992, já com a participação de Silvana Romana como co-editora. Até 1997 , a revista publicou 8 volumes, alguns com numeração dupla, e terminou nesse ano com o $\mathrm{n}^{\circ}$ 10/11.

Com essa experiência os dois editores estabeleceram contacto com inúmeros colaboradores brasileiros e estrangeiros, com quem passaram a manter um diálogo permanente. No entanto, a exigência crescente na produção da revista reflectia-se no aumento dos custos e tornava cada vez mais difícil a sua publicação com uma certa regularidade.

Procurando reagir a essas dificuldades logísticas, Abílio Guerra cria em 1996 o Boletim Óculum, uma publicação periódica mais informal, editada pela PUC-Campinas, com mais regularidade e com artigos mais curtos, que circulava por todo Brasil e que promovia o contacto entre investigadores com interesses comuns. O Boletim Óculum publicou-se até ao ano 2000, mas entretanto foi criada uma versão electrónica experimental, que o disponibilizava em rede para todo o mundo, e que permitiu aos seus responsáveis o conhecimento técnico que tornou possível a criação, nesse ano, do Portal Vitruvius.

Abílio Guerra e Silvana Romana criaram a Editora Romano Guerra, que é proprietária do Portal, e desde o início o Vitruvius funciona como uma editora de revistas, cada uma com uma área de interesse e uma linha editorial próprias. Actualmente, ambas as edições do Vitruvius - no Brasil e em Espanha - têm uma estrutura composta por três partes: 1) o diário (ou jornal), que é também a página de abertura, funciona como sumário de publicações em papel e cada título é um "link" para o desenvolvimento do respectivo artigo; 2) as revistas, a que se pode aceder também a partir da página principal, incluem 6 títulos, isto é, 6 publicações distintas, cada uma com seu formato próprio, em função do conteúdo e da orientação editorial; e 3) pesquisa, que é o sector onde se mantém disponível o conteúdo das edições anteriores, das várias entradas que tem o Portal, para além de um guia com informação sobre publicações de Arquitectura e divulgação das publicações da Editora Romano Guerra (embora estes dois serviços não estejam actualmente disponíveis).

A revista Arquitextos é uma publicação de carácter científico com elevada exigência na selecção dos artigos publicados, sujeitos à "avaliação cega" (blind review) de um conselho editorial internacional, constituído por professores universitários da América Latina, Europa e Estados Unidos.

Arquitecturismo é uma publicação mensal que explora de diversas formas a relação 
entre Arquitectura e Turismo. Drops publica artigos curtos com uma abordagem relativamente livre tratando de arquitectura, cultura e arte.

Embora o Portal tenha começado por se dedicar essencialmente à área específica de Arquitectura e do Urbanismo, ao longo do tempo foi alargando o espectro das matérias tratadas a outras áreas que lhe estão próximas - como o Design, a Sociologia Urbana e a Arte - procurando também aumentar o potencial público-alvo. Minha Cidade, que ajudou também a fazer essa evolução editorial, funciona como espaço de debate sobre questões urbanas concretas, onde os intervenientes podem expressar preocupações com a sua cidade. Entrevista inclui conversas com personalidades culturalmente relevantes e resenhasonline apresenta recensões de livros, revistas, teses, etc.

O Vitruvius Espanha, inaugurado em Março de 2010, apresenta o mesmo formato que o seu irmão brasileiro, diferindo apenas no conteúdo, que é especificamente dirigido à realidade ibérica e europeia.

Ao longo destes 10 anos, Abílio Guerra e Silvana Romano participaram em inúmeros eventos, promovendo e aprofundando colaborações tanto na América Latina como na Europa, sobretudo na Península Ibérica - Bienal Internacional de Arquitectura de São Paulo, Bienal Ibero Americana, Prémios Mies Van der Rohe, Ministério da Cultura e da Habitação em Espanha, Editorial Gustavo Gili, Universidade Politécnica da Catalunha...
E simultaneamente, foram acolhendo nas edições do Vitruvius a participação de inúmeros autores, particularmente de Espanha - como Josep Maria Montaner, Zaida Muxi, Iñaki Abalos, Hélio Piñon. Nos últimos anos, a colaboração dos arquitectos brasileiros Flavio Coddou e Márcio Cotrim, estabelecidos em Barcelona, permitiu o contacto permanente com a actualidade ibérica e europeia, possibilitando a criação aí de uma base editorial autónoma - o Vitruvius Espanha.

O Portal Vitruvius tem sido nestes 10 anos um dos principais meios de divulgação da Arquitectura em português. $\mathrm{Na}$ edição brasileira foram publicadas entrevistas a Nuno Teotónio Pereira, Eduardo Souto Moura, Carrilho da Graça, Manoel de Oliveira, entre outros. Na versão europeia, são permanentemente divulgados os principais acontecimentos anunciados pelo website da Ordem dos Arquitectos. Em Portugal, qualquer investigador da área da Arquitectura conhece a actividade do Portal, e usa-o em muitas situações.

Não é preciso esperar pela generalização do uso dos iPads (ou hardware semelhante) ou pela evolução editorial em curso, que está a levar à publicação simultânea em papel e em formato electrónico (e-books), para perceber a vantagem de uma plataforma editorial como o Vitruvius, que se constrói com os instrumentos tecnológicos mais actuais, e em certa medida mais estimulantes, sem abandonar os critérios de exigência mais rigorosos.

Nuno Correia 


\section{Título da página electrónica: Orçamento Participativo Portugal URL: http//www.op-portugal.org/}

Uma página de entrada para a participação

A página www.op-portugal.org foi criada em Março de 2008, no âmbito do projecto Orçamento Participativo Portugal, ${ }^{1}$ apoiado pela Iniciativa Comunitária EQUAL (Employment, Social Affairs and Equal Opportunities). A intervenção desenvolvida teve como objectivo geral disseminar o tema e a metodologia do Orçamento Participativo (OP) a nível nacional, através da organização de acções de formação, workshops, encontros nacionais e consultoria para as autarquias, entre outras acções.

Este site foi o primeiro a surgir em Portugal sobre este tema, oferecendo ao visitante um acervo informativo e documental bastante vasto e funcionando como porta de entrada para inúmeras outras páginas e redes de cooperação internacional dedicadas ao $\mathrm{OP}$, à participação e à democracia em geral.

O site tem servido de referência para muitos actores da sociedade portuguesa, com especial destaque para:

- técnicos e dirigentes de autarquias, assim como outros agentes ligados a partidos políticos, interessados em recolher mais informação que ajude a suportar a implementação de experiências de OP nos seus territórios;

- docentes e estudantes universitários empenhados em desenvolver trabalhos de investigação sobre o tema, em especial em áreas relacionadas com a sociologia, a ciência política e a administração pública; - grupos e movimentos sociais mais despertos para a intervenção cívica e com vontade

\footnotetext{
${ }^{1}$ Promovido pela Associação In Loco, em parceria com o Centro de Estudos Sociais, o Centro de Estudos e Formação Autárquica, a Câmara Municipal de Palmela, a Câmara Municipal de São Brás de Alportel e a Junta de Freguesia de Carnide.
}

de influenciar decisores políticos, a nível local, para a adopção de práticas de OP. A integração dos promotores desta iniciativa em diferentes redes de cooperação internacional fomentou igualmente uma procura do site por parte de agentes políticos e sociais de outros países e continentes. A publicação regular de notícias sobre experiências e eventos relacionados com OP, ocorridos noutras latitudes, permitiu produzir conhecimento sobre a expansão deste tipo de práticas a nível mundial, desmistificando algumas ideias, com especial destaque para duas:

- não se trata apenas de experiências pontuais em cidades pouco significativas, normalmente pertencentes a países considerados subdesenvolvidos ou em desenvolvimento. O OP está presente em todos os Continentes, em pequenas cidades, assim como em grandes metrópoles;

- não é uma prática exclusiva de partidos de esquerda. A espantosa disseminação do OP tem sido assumida por actores de diferentes quadrantes ideológicos, colocando-o acima dos tradicionais rótulos partidários.

As informações produzidas pelo sistema de monitorização e avaliação da página permitem retirar algumas conclusões que validam o interesse despertado em Portugal e no estrangeiro, durante estes dois anos de existência:

- mais de 17 mil visitas, das quais cerca de 12 mil feitas a partir de Portugal e 5 mil de outros 71 países de 6 continentes, com especial destaque para os de língua portuguesa e espanhola;

- visitantes nacionais oriundos de cerca de 140 localidades, com especial destaque para algumas capitais de distrito, como é o caso de Lisboa, Porto, Faro, Coimbra, Funchal, Braga e Aveiro; 
- cerca de 400 referências e links feitos em outras páginas electrónicas, que permitiram gerar mais de $20 \%$ do tráfego de visitantes do site.

A imagem de credibilidade e seriedade do trabalho desenvolvido no âmbito do projecto Orçamento Participativo Portugal, amplamente suportada pelo site na componente de informação e divulgação, levou inclusive algumas autarquias portuguesas a criar links directos a partir das suas páginas oficiais, como forma de associar e credibilizar as suas práticas locais.

A página do OP Portugal mereceu igualmente destaque em alguns sites oficiais de organismos públicos dependentes da Administração Central, como por exemplo: - a Plataforma Colaborativa da Rede de Centros de Recursos em Conhecimento, do Instituto do Emprego e Formação Profissional;

- a Rede Comum de Conhecimento, da Agência para a Modernização Administrativa.

A partir do trabalho levado a cabo e da percepção das dificuldades dos municípios, ao nível do desenvolvimento das práticas de $\mathrm{OP}$, foi criado um outro site, com uma componente claramente mais internacional - www.infoop.org - Sistema de Informação sobre Orçamentos Participativos. Este congrega duas grandes áreas de trabalho:

- um observatório internacional, que permite o registo e a georreferenciação de experiências e de redes de $\mathrm{OP}$, enquanto contributo para a criação de uma base de dados mundial sobre este tipo de práticas; - uma aplicação informática criada a nível mundial para apoiar a concepção, gestão, monitorização e avaliação de processos de OP.

Esta última não fornece receitas, nem procura padronizar experiências. A sua função é facultar elementos de suporte à estruturação deste tipo de processo, tendo por base critérios de exigência e qualidade das dinâmicas de participação.

A aplicação sustenta-se nos seguintes princípios:

- Reserva. Cada utilizador registado terá acesso a uma área reservada, no âmbito da qual poderá conceber, gerir e avaliar o seu processo de OP;

- Flexibilidade. Nenhum dos campos criados é de preenchimento obrigatório. O utilizador poderá utilizar a aplicação em função das características de maior ou menor complexidade da experiência de OP que conduz;

- Estruturação. A aplicação permite a organização e o acesso à informação através de um índice de módulos criado para o efeito, nomeadamente a "concepção", a "gestão" e a "avaliação" do processo;

- Inteligência. A aplicação está dotada de níveis elevados de inteligência, permitindo cruzar informação entre os diferentes módulos e calcular dados e indicadores de forma automática;

- Arquivo. O sistema informático foi concebido de forma a tornar possível a gravação de dados referentes ao OP, criando, desse modo, bases de dados e séries anuais detalhadas sobre todo o processo.

No módulo referente à "concepção", o utilizador terá como auxílio um conjunto bastante completo de questões que o ajudará a conceber de forma detalhada o seu processo de OP: o enfoque que pretende dar; a forma como vai dividir o território para promover a participação da população; a possibilidade de georreferenciar essa divisão territorial; a concepção dos instrumentos de participação; a definição da coordenação técnica e política do processo; o desenho do ciclo de participação; o enquadramento regulador do $\mathrm{OP}$, entre muitos outros aspectos.

No módulo de "gestão", o utilizador terá à sua disposição todos os elementos de que necessita para a operacionalização e 
implementação do OP, como por exemplo o desenho de um processo de formação interno e externo; a criação de um plano de comunicação e divulgação; a gestão das reuniões públicas, com a possibilidade de emissão das respectivas actas e relatórios, assim como o cálculo estatístico dos participantes; a gestão das propostas apresentadas, a sua análise técnica e definição das respectivas prioridades; a administração dos investimentos aprovados e incluídos no orçamento; a possibilidade da sua georreferenciação, entre muitos outros aspectos.

O módulo de "avaliação" está concebido de forma a permitir a monitorização e avaliação do processo, dos resultados e dos impactos do OP. Ao longo dos diferentes campos de trabalho, o utilizador será confrontado com estatísticas produzidas automaticamente pelo sistema (participantes, reuniões, propostas, investimentos, orçamento, etc.), assim como com diferentes instrumentos criados para a recolha e sistematização de informação referente a toda a dinâmica de participação. O mapeamento dos investimentos e a sua catalogação por áreas e domínios de intervenção é outra das inovações desta aplicação. O sistema permitirá também a realização de análises comparativas entre os processos, os resultados e os impactos de diferentes ciclos anuais de OP. Está ainda preparado para fornecer alguns dos instrumentos-tipo mais utilizados nestes processos, nomeadamente, fichas de presença nas reuniões públicas, fichas de caracterização dos participantes, fichas de apresentação de propostas, actas e relatórios, entre muitos outros.

Nelson Dias

\section{Título da página electrónica: OTAINSA y gestión del Parque Social de Vivienda de Sevilla URL: http://otainsa.blogspot.com}

La OTAINSA es la Oficina Técnica de Asesoramiento al Inquilino en Situación de Abuso creada en 2004 por el Ayuntamiento de Sevilla. Ganadora de varios premios de gestion urbana por su concepción innovadora, hoy está ubicada en la Gerencia Municipal de Urbanismo. Entre sus funciones, está la de intermediación entre inquilinos y propietarios, relaciones estas en las que las administraciones, por lo general, no intervienen por considerar que son propias del ámbito privado y no del público, su ámbito "natural" de intervención. La OTAINSA actúa ante situaciones en que las viviendas han llegado a una situación extrema de deterioro, por incumplimiento de la obligación de conservación de los edificios por parte de los propietarios, con la intención de estos últimos de que los inquilinos sean desalojados para la posterior demolición, rehabilitación y puesta en venta o alquiler del inmueble a precio de mercado actual. Esta secuencia ha marcado frecuentemente las prácticas españolas de transformación urbana en las últimas décadas. Principalmente ha sido motivada porque estas viviendas, situadas en los cascos históricos, habían sido habitadas por clases populares y trabajadoras en un momento en el que los centros de las ciudades no tenían ni el valor económico, ni la consideración social que actualmente han adquirido. En la mayoría de los casos, los inquilinos se encontraban sujetos a una ley que permitía mantener una "renta antigua", correspondiente a los precios de mercado del momento en que fueron arrendadas. Cuando en el Noviembre 1994 
entra en vigor la nueva Ley de Arrendamientos Urbanos (Ley 29/1994), las rentas antiguas quedan fuera de las revisiones sujetas al mercado inmobiliario actualizado, y el boom inmobiliario (con sus corolarios de especulación urbanística) amenazada la situación de muchos antiguos inquilinos, presionados por el interés de los propietarios de recuperar rápidamente la propiedad, para su puesta en el mercado a precios revisados.

Ante una situación en que un gran número de familias (especialmente personas mayores con escasos recursos y que mantienen sus redes de apoyo social en su barrio) se ven abocadas a la exclusión y a la segregación social y territorial, el configurarse de formas de "mobbing inmobiliario" repetidas, sobre todo por parte de empresas de intermediación, se impone la necesidad de una intervención pública capaz de actuar frente a la presión del mercado inmobiliario y a la especulación del suelo como fuente de riqueza en el proceso de acumulación del capital. ¿Qué pasa normalmente con los apartamentos y edificios ante el incumplimiento de la propiedad del deber de conservación del inmueble? A menudo se llega, por parte de la administración, a declarar el inmueble en "estado de ruina". Este es el paso previo para su desalojo, demolición y posterior rehabilitación. Una vez que se ha llegado a esta situación, la administración puede no actuar o buscar una solución al problema social que se ha originado. En este segundo caso, a los afectados se les busca una solución temporal de realojo, a veces en otros barrios, en casas de propiedad municipal, o alquiladas, hasta que éstos resuelven su situación de forma individual. En otros casos, la administración actúa habilitando viviendas de VPO (Viviendas de Protección Oficial) o posibilitando a los inquilinos su vuelta a la vivienda de origen, expropiando o comprando los inmuebles afectados.
Es en esta moldura que toma forma la OTAINSA, promovida por la misma coalición política (formada por el Partido Socialista e Izquierda Unida) que desde el 2004 ha impulsado en Sevilla procesos de diálogo social como los Presupuestos Participativos. El origen de esta nueva herramienta de control de las dinámicas territoriales está en la idea de que la difícil situación de muchos habitantes del casco antiguo de la ciudad -sujeto a varios procesos de renovación urbana desde el inicio del milenio- necesita de "firmes convicciones contra las desigualdades y el abuso a los más indefensos en materia de vivienda". En el caso de Sevilla, detrás de la decisión de crear la OTAINSA (con base en experiencias que ya existen también en otras ciudades españolas) estuvo la presión vecinal que ha sido decisiva para moldar una solución política innovadora, através de movilizaciones continuas desde los primeros años 90.

En torno a los avisos de desalojo anunciados en la zona norte del casco antiguo, sobre todo en la calle San Bernardo y en el Barrio de Triana, se crearon plataformas ciudadanas de apoyo a las personas afectadas. A estas se sumaron jóvenes, hijos en algunos casos de los afectados, y en otros, vinculados al movimiento "okupa", a los ecologistas y a otros movimientos alternativos urbanos, que reclamaban el uso social de las viviendas frente al uso especulativo del mercado. No obstante, la contribución principal a la creación de la OTAINSA vino de las asociaciones de vecinos de algunos barrios, movilizadas ante algunas posibles intervenciones urbanísticas. Todos estos grupos se aglutinaron en torno a "La Liga de Inquilinos", como espacio donde confluían las plataformas "Salvemos la Casa del Pumarejo" y "Salvemos San Bernardo".

Fue con el cambio de gobierno municipal en 2003 que el nuevo Ayuntamiento de 
Sevilla se planteó por la primera vez la idea de una intervención directa en situaciones donde los inquilinos se veían sometidos a situaciones de abuso inmobiliario. Desde la administración se hizo una apuesta por revalorizar las necesidades sociales frente al uso especulativo del suelo, interviniendo directamente en los litigios entre propiedad e inquilinos. En estos 6 años de actividad de la Oficina Técnica de Asesoramiento al Inquilino en Situación de Abuso, los departamentos municipales interesados actuaron sobre todo obligando a los propietarios a la conservación de los inmuebles, y procediendo - llegado el caso - a la expropiación o compra de las viviendas, para que fueran devueltas a sus inquilinos originarios. La Gerencia de Urbanismo ha construido o recalificado un parque de apartamentos dirigidos al realojo temporal de inquilinos, interviniendo en el mercado de creación de valores fundiarios a través de medidas públicas de carácter social que tienen la finalidad última de garantizar la vuelta de los inquilinos a sus viviendas primitivas, una vez que estas se encuentren en un estado digno de conservación y en consecuencia de habitabilidad.

El blog de la OTAINSA (al igual que otros websites que dedican espacio a su actuación, como http://www.acosomoral.org/ otainsa.htm) tiene el objetivo de reivindicar cómo la lucha contra el "mobbing inmobiliario" y por "el mantenimiento de la población residencial en sus espacios geográficos originarios" sean "un valor cultural y social de primer orden" además de una necesidad básica para "los moradores que defienden el arraigo en su medio territorial y social como uno de los elementos fundamentales de sus necesidades más vitales”.

Virginia Gutiérrez Barbarrusa

\section{Título da página electrónica: CIDLOT/Universidade de Cabo Verde URL: www.unicv.edu.cv/cidlot}

O Centro de Investigação em Desenvolvimento Local e Ordenamento de Território (CIDLOT) da Universidade de Cabo Verde representa um laboratório de ponta da primeira universidade pública do país, fundada apenas há quatro anos, que tem o objectivo de fazer dialogar o mundo académico com as maiores dinâmicas de desenvolvimento do arquipélago.

Desde a sua fundação em 2009, o CIDLOT tem trabalhado com vista a preencher uma série de lacunas de conhecimento existentes em Cabo Verde, por exemplo, realizando um levantamento da arquitectura habitacional no país. As bases metodológicas e conceptuais deste trabalho - que podem ser consultadas na página electrónica do centro - enraízam-se na consciência de que ainda hoje há uma escassa literatura de referência sobre a moradia cabo-verdiana, impedindo uma análise mais aprofundada e metodologicamente consistente sobre a relação arquitectura/ cultura/quotidiano no país.

Alguns estudos têm sido feitos a partir do património edificado, voltados, sobretudo, para os edifícios históricos administrativos e moradias senhoriais (os sobrados), ou para contextos específicos, como é o caso de Cidade Velha, declarada património da humanidade pela Unesco em 2009. Em Boa Vista foi recentemente publicado um livro sobre o património paisagístico, com breve descrição da morfologia habitacional no seu conjunto, mas não houve neste trabalho um levantamento específico das moradias isoladamente. Uma outra publicação recente relacionada, de certa maneira, com 
o tema habitacional é o Manual de Construção, orientado para a divulgação de práticas construtivas sustentáveis e adequadas ao clima local. Merece ser frisado que os planos directores municipais do arquipélago não têm incluído sistematicamente a questão habitacional. Por exemplo, o único PDM até hoje publicado - o da cidade da Praia - não apresenta nenhum capítulo dedicado à matéria, limitando-se a apresentar dados do Instituto Nacional de Estadística (INE) sobre o deficit habitacional.

Nesta moldura de total carência de literatura especializada em arquitectura habitacional no país, destinada a auxiliar tanto o governo quanto o mercado a direccionarem as suas acções às especificidades do seu público, o CIDLOT considera que "o conhecimento de si, para consolidar-se ou reinventar-se” deveria representar uma marca fundamental para o desenvolvimento de uma sociedade, assim evitando o risco de desperdiçar energia e recursos em projectos descolados da realidade e dos anseios locais. Hoje, em Cabo Verde, algumas perguntas básicas ainda necessitam urgentemente de respostas. Por exemplo: como é a disposição interna da casa cabo-verdiana? Quais os cómodos mais e menos usados? Quais os espaços de sociabilidade e de reclusão? Como se relaciona a moradia com os espaços de vizinhança? Há diferença entre as várias ilhas ou os diversos concelhos nos hábitos de morar? Quais as influências dos hábitos construtivos trazidos pelos emigrantes? Há uma contaminação significativa da população em diáspora das casas cabo-verdianas?

O "Diagnóstico da Arquitectura Habitacional em Cabo Verde" é o primeiro trabalho de investigação do CIDLOT e tem como objectivo principal identificar as principais tipologias arquitectónicas de função residencial em Cabo Verde, de modo a apoiar as estratégias e escolhas directivas de acções nesta área. Teve origem numa proposta do Plano Estratégico Nacional de Habitação, mas dado o seu carácter inovador e abrangente, a proposta foi inteiramente absorvida pela universidade, desvinculando-se do calendário governamental.

Em breves linhas é hoje possível afirmar que o crescimento rápido das cidades cabo-verdianas, com as imigrações/emigrações e, mais recentemente, com as influências e impactos do turismo em certas ilhas, conduziu a mudanças radicais nos hábitos de morar e nas tendências construtivas locais. Actualmente as disparidades económicas e sociais definidoras da sociedade são claramente espelhadas no território e nas zonas residenciais das cidades. A análise das habitações construídas tanto nos bairros de alto padrão económico como naqueles carenciados permite compreender o abandono de certas práticas culturais de habitar e a afirmação de outras.

A solidificação dessas desigualdades tem eliminado a comunalidade dos modos de habitar tradicionais do cabo-verdiano, característica anteriormente definidora de espaços de sociabilidade. Antigamente, os locais de convívio ao redor das residências compunham uma relação orgânica entre a habitação e as demais zonas do habitat. A transição entre o exterior e interior das casas, aliada aos espaços entre os conjuntos construídos, proporcionava uma dinâmica social e comunitária importante dentro e fora da habitação. Muitos destes elementos estão hoje a ser perdidos. Nos bairros de alto padrão económico há frequentemente uma escassez de áreas de interacção entre a moradia e o espaço público. O resultado é um conjunto pouco ou nada comunitário, composto de fachadas estáticas a minar o que tecnicamente é designado por "unidades de vizinhança": as fachadas perdem a função de membrana de transição entre o público e privado e adquirem um valor 
de ostentação. Este processo é indicador de uma sociedade em crise identitária e de valores: o ter sobrepõe-se ao ser e o individual ao colectivo.

Sob este aspecto têm sido importadas concepções construtivas muitas vezes não adequadas ao clima e à cultura nacional. O estudo dessas tendências - claramente um dos objectivos nodais do "Diagnóstico da Arquitectura Habitacional em Cabo Verde" - é essencial para a compreensão do presente e a projecção do futuro da sociedade do arquipélago, procurando soluções mais adequadas à equidade social. Hoje em dia, as forças económicas e sociais que redesenham o território cabo-verdiano influenciam de igual modo as suas tendências construtivas e hábitos de morar. Tais forças exercem uma poderosa pressão, levando ao abandono de certas práticas e à adesão a soluções pouco adequadas ao ambiente e à coesão espacial e social. É portanto imperativo conhecer as tradições de construção, as práticas culturais e as novas tendências para orientar políticas adequadas ao país. Conhecer - no entendimento do "Diagnóstico" que está hoje a ser concluído - torna-se o elemento central para "se reconhecer e para desenvolver".

Deve frisar-se que a opção metodológica deste diagnóstico partiu da valorização do saber local para a definição de zonas tipologicamente homogéneas, ou seja, para delimitar as tipologias habitacionais predominantes em cada um dos concelhos do arquipélago. Com este objectivo foi realizada uma oficina preparatória do diagnóstico, para a qual técnicos municipais de todas as Câmaras trouxeram amplo material visual da morfologia habitacional de cada um dos territórios. Investigadores, arquitectos e demais envolvidos debruçaram-se conjuntamente sobre este material durante toda a jornada. O resultado foi a definição de três a sete tipologias predominantes por concelho, as quais seriam depois levantadas detalhadamente no terreno pela equipa da universidade. A participação conjunta das equipas técnicas das Câmaras Municipais e da universidade tem sido fundamental para os bons resultados da investigação. O website relata como mais de $85 \%$ das 22 Câmaras Municipais aderiram a esta investigação (à excepção de São Vicente, Tarrafal de São Nicolau e Ribeira Grande de Santiago).

Até Março de 2010 foram realizados levantamentos em Santo Antão, São Vicente, São Nicolau, Sal, Boa Vista e Maio, cujo resultado está a ser preparado para publicação do primeiro volume do livro Panorama da Arquitectura Habitacional em Cabo Verde. A falta de recursos tem adiado a finalização do levantamento nas ilhas de Fogo, Brava e Santiago, o qual comporá o segundo volume da publicação. No final, cerca de cem moradias de todo o território nacional irão ser detalhadamente catalogadas com fotografias, plantas, cortes, fachadas e delongadas entrevistas com os seus moradores, a fim de solidificar a compreensão socioespacial de cada habitação e do conjunto tipológico. Para a coerência e uniformidade de linguagem dos dados visuais arrolados, optou-se pela inclusão de um fotógrafo profissional na equipa da universidade.

Um dos dados significativos da sondagem no terreno diz respeito ao conforto térmico das habitações, para o qual se tem utilizado um termómetro capaz de medir simultaneamente a temperatura interior e exterior das moradias. Alguns dados preliminares têm revelado uma temperatura até $10^{\circ} \mathrm{C}$ mais elevada no interior, bastante desconfortável para um país com uma média térmica anual de cerca de $25^{\circ} \mathrm{C}$. Ademais, análises arquitectónicas e sociológicas do ponto de vista do património histórico, da eficiência energética e da relação entre género e moradia têm 
sido acolhidas nesta pesquisa. $\mathrm{O}$ resultado será a primeira publicação de âmbito nacional sobre a arquitectura habitacional, um estudo de referência que certamente responderá a algumas destas questões e abrirá novas hipóteses de investigação científica na área.

Merece salientar-se a importância de conhecer os hábitos de um povo, seja para as empresas atenderem a novos mercados emergentes como para o governo desenhar as suas políticas habitacionais. Isto é, toda a sociedade precisa de se conhecer para melhor atender aos seus défices, demandas e desejos. A moradia diz respeito à realidade e também às subjectividades de um povo. Como pode a arquitectura responder aos sonhos das pessoas sem perder o contacto com a realidade? No contexto cabo-verdiano, com condicionantes específicas de clima, de economia e de materiais, como podem todos os envolvidos na construção habitacional, dos técnicos, às empresas e governo, actuar em sintonia com os hábitos e o desenvolvimento futuro do país?
Sem conhecer como se mora e quem mora muitos projectos estão fadados ao insucesso. Até hoje, governos e empresários têm investido muito dinheiro em soluções inadequadas: está-se a construir para o cabo-verdiano real? Com materiais adequados? Qual é a qualidade das moradias em termos de eficiência energética e resposta às necessidades das famílias? Como é que as novas tendências habitacionais definirão dinâmicas sociais futuras?

Para destrinçar estas perguntas simples, a Universidade de Cabo Verde, através do CIDLOT, decidiu realizar o diagnóstico $\mathrm{da}$ arquitectura habitacional, que constitui um levantamento inédito no país. Esta pesquisa tem, ademais, servido de base ao que poderá vir a ser um futuro programa de mestrado em arquitectura e desenvolvimento sustentável. Esta é uma das maneiras como a investigação e a universidade podem efectivamente colaborar em prol do desenvolvimento local: conhecer e reconhecer para desenvolver.

Andréia Moassab e Patrícia Anahory 